\title{
Ensenyar ciències i anglès a través de la docèn- cia compartida
}

\author{
Laura Valdés (lauravaldessanchez@gmail.com) \\ Mariona Espinet (mariona.espinet@uab.cat) \\ Departament de didàctica de la matemàtica i les ciències experimentals. UAB.
}

En el context de l'Europa multicultural i d'un món globalitzat han fructificat les polítiques lingüístiques que promouen l'aprenentatge de llengües diferents a la llengua materna. En l'àmbit educatiu es promou l'aprenentatge de l'anglès, com a llengua franca de la comunitat econòmica europea, i l'enfocament AICLE (Aprenentatge Integrat de Contingut $i$ Llengua Estrangera), en el que una llengua estrangera és usada com a llengua d'instrucció d'altres matèries com per exemple les ciències, es troba vivint un procés d'expansió a Catalunya $i$ arreu d'Europa. Ensenyar les ciències en anglès suposa un repte important per al professorat del nostre país. Tot seguit reflexionarem sobre alguns aspectes d'aquest enfocament a partir d'una experiència d'educació científica realitzada en una escola d'Educació Primària que ha aconseguit avançar en el plantejament d'un projecte AICLE. Es tracta del Taller Science que es realitza mitjançant la docència compartida, és a dir, el treball col-laboratiu de dues mestres que comparteixen l'espai i la responsabilitat de l'aula. Retratarem l'aprenentatge recíproc que s'ha produït entre les mestres en base a: (a) una evolució en l'estructura del Taller, (b) l'assoliment d'una responsabilitat compartida a l'aula $i$ (c) un traspàs entre mestres de la capacitat de formular preguntes científiques.

Paraules clau: AICLE, docència compartida, interacció, didàctica de les ciències, formació del professorat, Primària

In the context of a multicultural Europe and a globalized world, language policies have arisen to promote the learning of languages other than the mother tongue. In the European Economic Community educational policies promote the learning of English as a lingua franca. CLIL approach (Content and Language Integrated Learning), in which a foreign language is used as a language of instruction in other subjects such as science, is experiencing an expansion in Catalonia and throughout Europe. Teaching Science in English is a major challenge for teachers in our country. This paper presents a Science Education CLIL experience that promotes scientific inquiry in the primary school. Teachers involved in this experience use coteaching, that is, a mode of collaboration where two or more specialists share teaching responsibilities inside and outside the classroom. The results of the research indicate that coteaching facilitates a reciprocal learning among teachers in the following areas: (a) a change in the structure of the workshop, (b) a shared responsibility in the classroom, and (c) a transfer among teachers of the ability to formulate scientific questions.

Keywords: CLIL, coteaching, interaction, science education, teacher training, Primary education

\section{INTRODUCCIÓ}

Les polítiques educatives europees, estatals i autonòmiques promocionen, mitjançant la posada en marxa de diversos plans educatius (com el Programa de Educación Bilingüe o PEB espanyol o el Pla Integrat de Llengües estrangeres o PILE català), l'aprenentatge de l'anglès de forma integrada a 
altres continguts. A Catalunya han proliferat els centres escolars que integren l'aprenentatge de les ciències i l'anglès, doncs es considera que l'AICLE (Aprenentatge Integrat de Contingut i Llengua Estrangera) suposa un benefici tant per a l'ensenyament-aprenentatge de la llengua estrangera (Vallbona, 2011; Gajo, 2007; Dalton-Puffer, 2007) com del contingut, en aquest cas les ciències (Canet i Evnitskaya, 2011; Moate, 2011; Gajo, 2007).

Tot i això, cal resoldre algunes dificultats teòriques i pràctiques d'aquest enfocament. El professorat implicat en aquests projectes es veu en la difícil situació d'adquirir el doble rol de professors de llengua estrangera i de ciències, tot i ser especialistes en l'ensenyament de només una d'aquestes dues disciplines. Cal establir doncs un diàleg disciplinar entre especialistes si volem avançar cap una vertadera integració de l'aprenentatge de les dues matèries sense renunciar a un ensenyamentaprenentatge de qualitat, tant de les ciències com de l'anglès.

No existeix però, un model de col·laboració únic entre el professorat AICLE. A les escoles podem trobar diversos models de col-laboració o fins i tot docents que assumeixen el repte tot sols. En aquest article volem presentar la docència compartida, entesa coma un model de col-laboració en el que els dos especialistes comparteixen totes les etapes del procés d'ensenyament-aprenentatge, inclosa l'aula, com un model de collaboració que aporta beneficis als projectes AICLE i a la formació del professorat implicat. Per fer-ho analitzarem l'experiència de dues mestres de Primària que van iniciar al seu centre el Taller Science, un taller internivell que treballava la ciència indagadora i l'anglès. Aquesta experiència ha estat analitzada per les pròpies mestres i per algunes investigadores en didàctica de les ciències $i$ de la llengua estrangera en el marc del projecte de recerca DALEAPECs (Academic Discourse in a Foreign Language: Learning and Assesment of Science Content in the Multilungual CLIL Classroom), projecte de recerca en contextos AICLE que du a terme un equip multidisciplinar format per professorat AICLE i investigadores en didàctica de la llengua estrangera i didàctica de les ciències.

\section{FER CIÈNCIES EN ANGLÈS A L'ESCOLA}

\section{L'enfocament AICLE}

Eurydice defineix AICLE (Aprenentatge Integrat de Contingut i Llengua estrangera) com un "terme genèric per a descriure qualsevol disposició en la que una segona llengua (estrangera, regional o minoritària i/o una altra llengua oficial de l'estat) s'empra per ensenyar certes matèries del currículum més que per a donar lliçons sobre el llenguatge en si mateix". (Eurycide 2006, p.8)

Aquest enfocament sorgeix com a resposta a una demanda social: la necessitat de formar ciutadans capaços de parlar diverses llengües per a poder conviure i treballar en un món globalitzat i multicultural. La llengua és entesa com a eina de cohesió social, d'integració i de comprensió mútua. L'anglès es considera la llengua franca de la comunitat Econòmica Europea i dels negocis a nivell internacional, i per tant un factor clau per a l'ocupació i l'èxit de les empreses. No és estrany doncs, que a nivell educatiu sorgeixin estratègies per a millorar l'aprenentatge de les segones o terceres llengües, especialment l'anglès, i l'AICLE va guanyant força com una manera de convertir l'escola en un ambient natural d'aprenentatge d'una llengua estrangera (Dalton-Puffer, 2007).

\section{Beneficis i reptes de l'AICLE}

Ara bé, engegar un projecte AICLE va més enllà de començar a impartir una assignatura en una altra llengua. Implica la necessitat de reflexionar sobre la millor manera de dur a terme una vertadera integració entre els objectius d'aprenentatge de dues matèries sense renunciar a un ensenyament de qualitat.

Per a Gajo (2007) la integració entre llengua i contingut es dóna en el complex procés interactiu i discursiu, que és rellevant per a ambdues disciplines, doncs el lèxic $\mathrm{i}$ les estructures discursives que utilitzen alumnes i mestres impliquen un coneixement tant del llenguatge com de la disciplina curricular que s'ensenya. En el camp de l'educació científica, altres autors com Sanmartí (2002), Mortimer i Scott (2003), Edwards i Mercer (1998) també defensen la idea de que aprendre ciències vol dir aprendre a parlar $i$ a escriure ciència. Per tant, aprendre ciències $i$ anglès de manera integrada suposa desenvolupar les competències cognitivolingüístiques pròpies de les ciències utilitzant una 
llengua estrangera, i per tant treballant alhora la competència comunicativa en aquesta llengua.

Diverses recerques han documentat els beneficis que aporta l'enfocament AICLE a alumnes i professorat.

Des d'un punt de vista sociocultural de l'ensenyament-aprenentatge, Moate (2011) defensa que l'AICLE millora l'aprenentatge de l'alumnat doncs implica més focalització en el llenguatge mitjançant l'augment del diàleg, de la negociació, de la participació, de l'ajuda per entendre el contingut, de la cultura del parlar, del temps per pensar, de l'atenció i de l'ús de sistemes de comunicació alternatius. Propicia per tant una millora de l'ensenyament - aprenentatge tant de la llengua estrangera com de les ciències.

La majoria de recerques en contextos AICLE s'han dut a terme des del camp de la didàctica de la llengua. Vallbona (2011) defensa que aquest enfocament millora el nivell de vocabulari i de gramàtica, motiva la independència dels estudiants, millora l'alfabetització en la llengua de l'escola, motiva l'espontaneïtat lingüística, desenvolupa habilitats d'estudi, genera consciència cultural, serveix per incrementar la presència de l'anglès sense incrementar les hores de llengües, genera actituds positives i motiva als estudiants alhora d'aprendre altres llengües.

Respecte a l'aprenentatge de les ciències, Canet i Evnistkaya (2011) assenyalen que millora l'aprenentatge del contingut científic doncs es treballa més en grup, l'atenció es centra més en l'estudiant i es generen més bastides d'aprenentatge. Una de les raons d'aquest tret AICLE podria ser que es potencia la interacció verbal per tal de facilitar l'adquisició de la competència comunicativa. Aquests autors defensen també que l'AICLE genera contextos d'aprenentatge més atractius i participatius, i que pel professorat suposa repensar les metodologies didàctiques, aprendre noves maneres d'ensenyar, collaborar amb d'altres professors o especialistes i tenir una feina més creativa, divertida i auto-reflexiva.

Tot i aquests avantatges els programes AICLE presenten uns reptes importants. Una revisió de la literatura ens ha permès identificar com a dificultats més importants que han de superar els docents AICLE: la manca de materials adaptats, la possibilitat d'oferir als alumnes una exposició adequada a la llengua estrangera, la tensió entre l'ensenyament de la llengua i l'ensenyament de les ciències i la manca de formació específica (Esco- bar Urmeneta, 2011; Dalton-Puffer, 2007). A més, com hem dit, l'especialització del professorat del nostre país, que és especialista en només una disciplina a l'educació secundària o bé un mestre generalista que no inclou una especialització en llengua estrangera en l'educació primària, suposa la necessitat d'establir models de collaboració entre docents. Sovint però, el professorat AICLE s'enfronta sol a aquest repte.

\section{La docència compartida, un motor de canvi}

Davant dels reptes AICLE presentats sorgeix la necessitat d'identificar estratègies docents per al desenvolupament d'aquests tipus de projectes. La docència compartida esdevé doncs una estratègia interessant doncs promou la col-laboració estreta entre docents especialitzats en les disciplines que es pretenen integrar.

Quan parlem de docència compartida ens referim una pràctica en la que "dos o més professors (...) planifiquen, instrueixen i avaluen conjuntament (...), un procés i no pas un resultat final" (Davis Willey i Crespo, 1998). Es correspon amb el terme anglès co-teaching i implica un treball col-laboratiu dins i fora de l'aula.

Els beneficis del co-teaching han estat documentats per diverses recerques: propicia l'observació de punts de vista diversos, genera un ambient de treball col-laboratiu, millora la participació de l'alumnat doncs genera una atmosfera oberta i d'intercanvi, exposa a diferents bagatges, propicia l'autoreflexió i l'autocrítica per part del professorat, ajuda als docents a aprendre noves estratègies i a conèixer noves perspectives sobre el coneixement i fa incrementar el sentit de comunitat afectant positivament a la cultura i l'ambient de l'escola (Davis-Willey i Crespo,1998).

En el camp de la Didàctica de les ciències Roth i Tobin (2009) defensen la docència compartida com a eina de desenvolupament professional del professorat. Consideren que els docents que treballen conjuntament a l'aula fan incrementar mútuament el seu espai de maniobra mitjançant la seva presència i les seves accions, i així milloren la manera com aprenen els estudiants i també ells mateixos. Des d'una visió vigotskyana, els docents aprenen dins la seva Zona de Desenvolupament Proximal gràcies als recursos que provenen de l'ensenyament de l'altre. Aquests autors han observat com, en només un parell de mesos, s'observen canvis en la manera d'ensenyar dels docents. Els 
seus estils tendeixen a convergir de manera que es van sincronitzant paulatinament, repartint-se efectivament l'espai i el temps. Però no només milloren la seva coordinació sinó que també expandeixen les seves identitats a través d'una cooperació que s'estableix en base a uns objectius i interessos comuns, i fent això incrementen els seus recursos per aprendre com ensenyar mentre es centren en millorar l'aprenentatge dels seus alumnes (Roth i Tobin, 2004).

En els contextos AICLE relacionats amb les ciències la pràctica de la docència compartida pot aportar elements que ajudin a superar els reptes plantejats, tal com es mostra a la Taula 1.

\begin{tabular}{|c|c|}
\hline $\begin{array}{l}\text { Reptes de } \\
\text { l'AlCLE }\end{array}$ & $\begin{array}{l}\text { Aportacions de la docèn- } \\
\text { cia compartida }\end{array}$ \\
\hline $\begin{array}{l}\text { Materials adap- } \\
\text { tats }\end{array}$ & $\begin{array}{l}\text { Pot afavorir una planificació } \\
\text { conjunta de nous materials i la } \\
\text { col·laboració d'experts en } \\
\text { llengua i ciències per a la rea- } \\
\text { lització d'aquests }\end{array}$ \\
\hline $\begin{array}{l}\text { Exposició ade- } \\
\text { quada a la L2 }\end{array}$ & $\begin{array}{l}\text { Presència a l'aula d'un expert } \\
\text { en llengua en tot moment }\end{array}$ \\
\hline $\begin{array}{l}\text { Tensió ciències - } \\
\text { anglès }\end{array}$ & $\begin{array}{l}\text { La planificació i instrucció } \\
\text { conjunta per part d'experts en } \\
\text { ciències i anglès propicia la } \\
\text { preocupació pels objectius } \\
\text { d'ambdós àmbits }\end{array}$ \\
\hline $\begin{array}{l}\text { Formació del } \\
\text { professorat }\end{array}$ & $\begin{array}{l}\text { Pot afavorir: } \\
\text { - L' aprenentatge recíproc } \\
\text { - L' increment de la capacitat de } \\
\text { maniobra } \\
\text { - L'autocrítica i la reflexió } \\
\text { - Discussions constructives }\end{array}$ \\
\hline
\end{tabular}

Taula 1. Aportacions de la docència compartida als reptes AICLE (Valdés et al, 2012)

\section{La ciència indagadora i la importàn- cia de les bones preguntes}

El projecte d'aprenentatge integrat sobre la que reflexionarem en aquest article és una experiència de docència compartida basada en la ciència indagadora i la llengua anglesa.

Quan parlem d'un enfocament indagatiu de l'ensenyament - aprenentatge de les ciències ens referim a una manera de plantejar la ciència escolar que suposa "ajudar als alumnes en el desenvolupament de processos dialògics per ser capaços tant de construir com d'avaluar afirmacions científiques", un enfocament que suposa que es doni l'oportunitat "d'explorar i criticar la relació entre les evidències i les explicacions" (Grandy i Duschl 2008, p. 316).
Per tal d'aconseguir que els alumnes construeixin el coneixement de manera dialògica, cal que mobilitzin coneixements, elaborin teories i les contrastin amb les evidències que provenen de l'experimentació, i el/la mestre/a els pot oferir bastides per a aconseguir-ho mitjançant la realització de bones preguntes.

Com remarquen Márquez i Roca la capacitat de plantejar bones preguntes, que sorgeixen del diàleg entre la teoria i els fenòmens observables, és fonamental per al desenvolupament de la ciència. De la mateixa manera les preguntes són fonamentals en el procés d'ensenyament-aprenentatge de la ciència escolar, així com ensenyar als alumnes a fer-se preguntes sobre els fenòmens. "Ensenyar i aprendre és, bàsicament, un procés de comunicació entre l'alumnat, el professorat i el coneixement, i en aquest procés les preguntes compleixen un paper fonamental" (Márquez i Roca, 2006).

Un docent que tingui cura del tipus de preguntes que fa als seus alumnes i que promogui moments de comunicació d'estil dialògic-interactiu en termes de Mortimer (2003), és a dir, moments en que escolti i prengui en consideració el punt de vista dels alumnes, aconseguirà el doble objectiu de fer pensar als alumnes i construir el seu coneixement alhora que els hi dóna oportunitats d'utilitzar el llenguatge de la ciència escolar, motivant el seu aprenentatge. En el cas d'un projecte AICLE, afavorir la participació dels alumnes mitjançant preguntes potencia també l'ús de la llengua estrangera i per tant el desenvolupament de la competència comunicativa en aquesta llengua.

\section{UN EXEMPLE D'EXPERIÈNCIA AICLE BASADA EN LA DOCÉNCIA COM- PARTIDA: EL TALLER SCIENCE}

\section{En què va consistir el taller?}

El Taller Science és una experiència d'AICLE en la que dues mestres, una mestra de ciències i una mestra especialista en anglès, han dut a terme una docència compartida durant dos cursos. Es va dur a terme a una escola pública de Primària de Sant Cugat del Vallès. Aquesta escola té un alumnat de perfil socioeconòmic variat provinent de diferents parts de la ciutat i forma part de la xarxa d'escoles del programa Agenda 21 Escolar municipal. El curs $2008 / 2009$ va sol-licitar un projecte PELE d'avançament de la llengua anglesa a 2on curs d'educació infantil (P4). En el moment que els primers alumnes PELE van arribar a primària 
(2010/2011) es va veure la necessitat de donar una continuïtat en el tractament d'aquesta Ilengua. Es van cercar doncs espais on poder utilitzar una llengua no vehicular en contextos significatius.

Va ser així com durant el curs 2010-2011 es va aprofitar una organització que ja funcionava a l'escola, els tallers inter-nivell, per engegar un projecte AICLE vinculat a les ciències experimentals: el Taller Science. Els tallers tenien una durada de 5 sessions d'una hora que es repartien durant una setmana, tot i que durant el curs 2011-2012 es van escurçar a 3 sessions d'una hora. Els alumnes que assitien al Taller Science ho feien en grups de 1416 nens i nenes de primer, segon i tercer de Primària, barrejats per nivells, $i$ aquest es repetia fins a que tots els nens de primer cicle de l'escola hi haguessin assistit. Després d'un primer Taller de 5 sessions en el que es van tractar temes referents a l'aire durant el curs 2012-2011, el curs següent (2011-2012) es van dur a terme dos tallers, de 3 sessions cadascú, que utilitzaven l'hort de l'escola per treballar conceptes relacionats amb la germinació i el creixement de les plantes.

Les mestres realitzaven la planificació i la instrucció del Taller col-laborativament. Programaven els objectius de cada Taller agrupats en tres blocs: els objectius propis de l'ària de Coneixement del Medi Natural, els objectius propis de l'ària de Llengua Estrangera i els objectius AICLE o integradors d'ambdues àries.

El Taller promovia un ensenyament - aprenentatge de les ciències basat en la indagació, doncs basava les lliçons en les teories i observacions dels alumnes, que les mestres feien sorgir mitjançant la realització de bones preguntes. Buscava a més la integració real del contingut científic amb el contingut de llengua anglesa de manera que la construcció lingüística en anglès fos el resultat d'una construcció científica basada en la experiència i el pensament.

Respecte a la llengua utilitzada pels participants del taller la mestra de ciències parlava en català i la mestra d'anglès ho feia sempre en anglès, mentre que els alumnes podien parlar en l'idioma que escollissin, tot i que en certs moments se'ls hi demanava explícitament que diguessin algunes paraules en anglès.

Els materials utilitzats en les sessions eren variats, molt vivencials i canviaven en funció de les activitats plantejades. A més es va crear el blog Superscience per tal de fer efectiva la comunicació d'allò après a les sessions de tallers amb les famílies. Cada grup d'alumnes escollia el contingut que volien publicar en aquest espai virtual, que es redactava col-laborativament en llengua anglesa.

\section{Continuïtat del taller}

Durant el present curs (2012-2013) l'escola s'ha vist forçada a eliminar l'estructura de tallers internivell, però ha decidit donar continuïtat al projecte AICLE de docència compartida i ha preservat l'espai anomenat Science amb alguns canvis organitzatius.

Actualment l'escola ha ampliat els equips de docència compartida i durant aquest curs la mestra d'anglès treballa col-laborativament amb tres mestres de 3er de Primària i un mestre de 4rt, encabint el taller Science dins l'assignatura Coneixement del Medi Natural i Social, aprofitant una de les 4 hores setmanals dedicades a aquesta matèria.

\section{Alguns resultats de l'experiència de docència compartida al Taller Scien- ce}

El Taller Science ha estat valorat per les pròpies mestres que l'han dut a terme i per un equip multidisciplinari d'investigadors en Didàctica. Les docents formen part del projecte de recerca DALEAPECS (Academic Discourse in a Foreign Language: Learning and Assesment of Science Content in the Multilungual CLIL Classroom). Es tracta d'un grup multidisciplinari d'investigadors i docents que focalitza el seu treball de recerca en situacions AlCLE vinculades a les ciències. La sevametodologia de treball consisteix en la integració d'activitats d'anàlisi de la interacció i de reflexions autocrítiques de la pràctica basades en la observació de vídeos.

Durant el curs 2011-2012 es va realitzar el treball de fi de màster "Construint l'aprenentatge integrat de ciències $i$ anglès a Primària. Retrat d'una evolució fruit del coteaching i la pràctica autoreflexiva" (Valdés i Espinet, 2012)Aquest treball retrata l'evolució d'aquest projecte AICLE de docència compartida $\mathrm{i}$ de les pròpies mestres mitjançant l'anàlisi de les preguntes que aquestes realitzen. Alguns dels seus resultats conclouen que la docència compartida ha propiciat un aprenentatge recíproc entre les mestres que s'ha traduït en:(a) una evolució en l'estructura del Taller, (b) l'assoliment d'una responsabilitat compartida a l'aula i (c) un traspàs entre mestres de la capacitat de formular preguntes científiques. 


\section{a) Evolució de l'estructura del Taller Science}

Les mestres relaten l'evolució en l'estructura de les sessions. Declaren que varen començar l'experiència amb una estructura força rígida: les sessions les començava dinamitzant la mestra d'anglès, repassant vocabulari i presentant el que es faria en la sessió d'aquell dia; el desenvolupament de la sessió el portava a terme la mestra de ciència, conduint la conversa científica; i el tancament de la sessió el feia la mestra de llengua, que ajudava a construir als alumnes una frase en anglès que resumís les idees científiques que havien sorgit al taller. Durant el segon curs però, la organització del taller va variar força; la mestra de ciències treballava els continguts científics amb la mestra d'anglès prèviament $i$, tot i que continuaven tenint cert ordre en les seves tasques, el paper de cadascuna d'elles es va anar desdibuixant i realitzaven una feina molt més col-laborativa. (Dallari et al, 2012).

El taller ha passat d'una organització en la que es separaven els moments de posar atenció en la construcció del coneixement científic (majoritàriament en català) dels moments d'especial atenció a la llengua anglesa, a un plantejament en el que la conversa científica es construeix en anglès i la metareflexió sobre la llengua estrangera sorgeix de manera espontània.

\author{
b) Assoliment de la responsabilitat compar- \\ tida a l'aula
}

No només s'han eliminat les fronteres entre els moments de treball amb la ciència escolar $\mathrm{i}$ moment s de focalització en el llenguatge, sinó que les dinàmiques de participació han evolucionat cap a una distribució dels torns de paraula de forma més uniforme i les converses, tot i que iniciades i/o portades per una de les mestres, incorporen comentaris i suport de l'altra mestra generant entorns d'interacció de les dues docents amb el grup classe. S'ha passat d'una organització en la que cada mestra monopolitza la conversa amb els alumnes en determinats moments de treball de la seva disciplina, a una organització menys rígida en la que les converses són portades per les dues mestres alhora.

Les Figures 1 i 2 mostren l'evolució en el torn de paraula analitzat en les transcripcions de dos fragments d'uns 13 minuts cadascun, el primer corresponent al curs 2011-2011 i el segon corresponen al següent curs. En tots dos fragments es du a terme l'explicació d'un experiment científic. Com mostra la Figura 1, durant el primer curs del Taller el torn de paraula anava majoritàriament dels alumnes a la mestra de ciències i d'aquesta als alumnes. La Figura 2 ens mostra com el torn de paraula es distribueix entre les dues mestres i el grup classe d'una forma més equilibrada durant el segon curs.

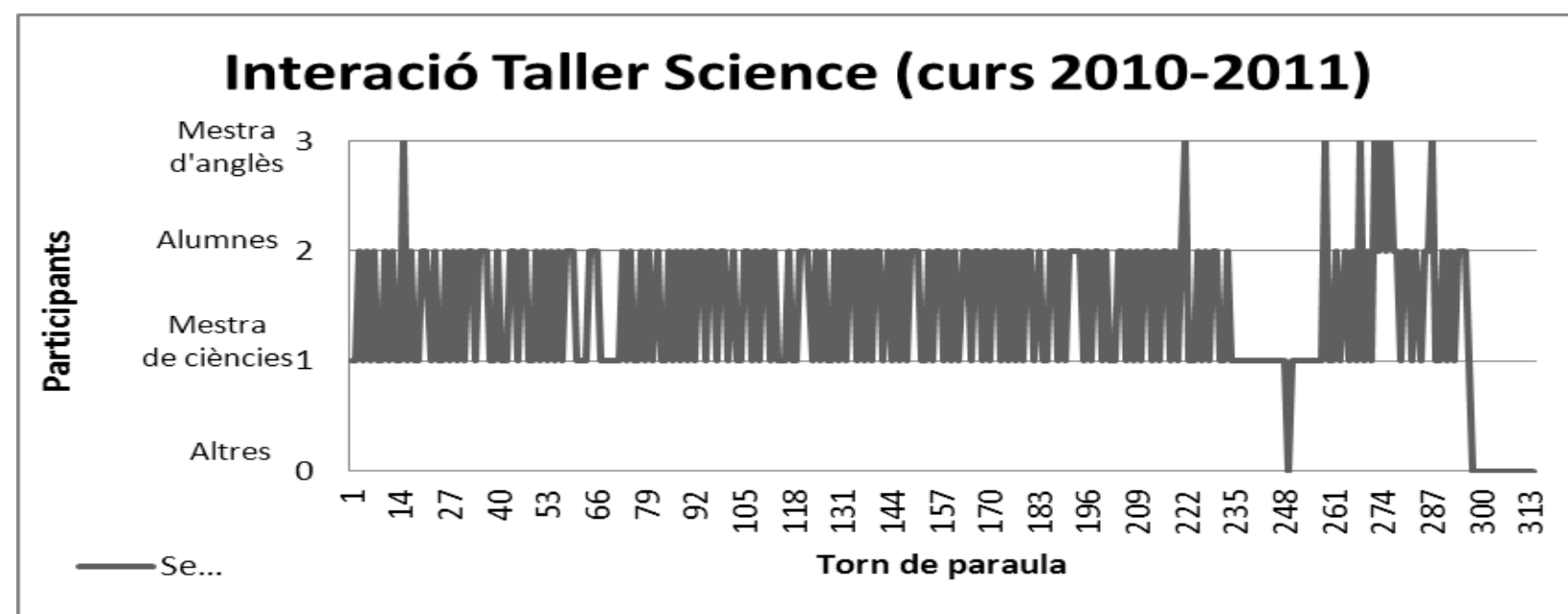

Figura 1. Torns de paraula Taller curs 2010-2011 


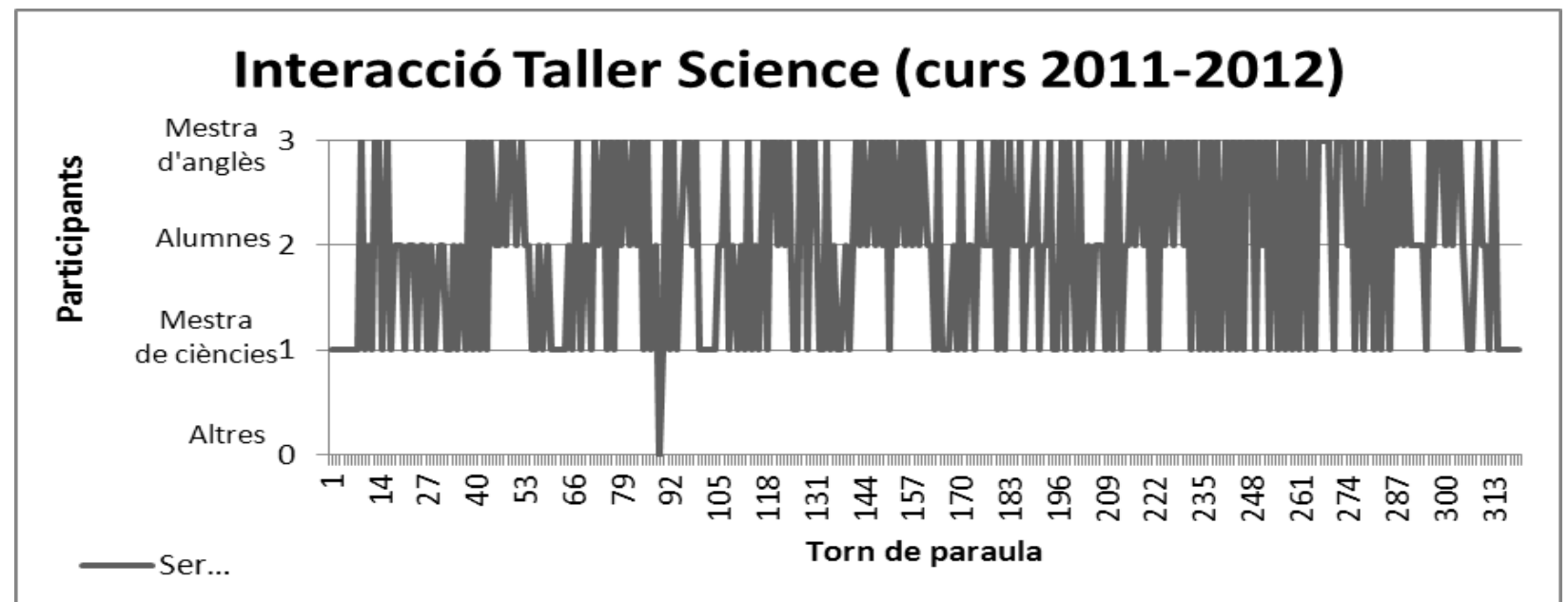

Figura 2. Torns de paraula taller curs 2011-2012

c) Traspàs entre mestres de la capacitat de formular preguntes científiques i lingüístiques

Com hem vist en els apartats (a) i (b) s'ha donat un traspàs de la conducció de la conversa científica a la mestra d'anglès. Aquest traspàs ha estat intencionat $i$ ha sigut possible ja que la mestra d'anglès ha incrementat la seva capacitat de maniobra gràcies al temps de docència compartida amb la mestra de ciències, i ha adquirit una nova identitat que li permet sentir-se còmode en el rol de mestra de ciències. Conduint converses científiques en anglès, aquesta docent genera moments d'integració entre ambdues disciplines (Gajo 2007).

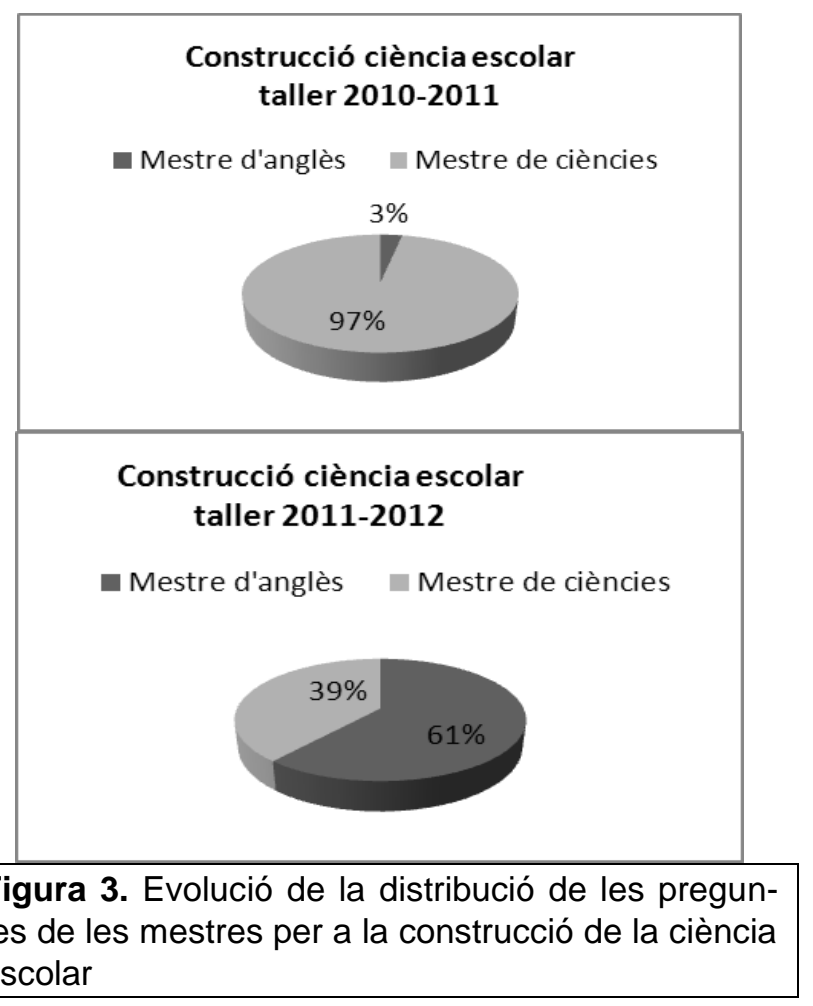

Es va realitzar un anàlisi de les preguntes de les mestres en els dos fragments de 13 minuts corresponents al primer i segon any del Taller. La Figura 3 ens mostra com la mestra d'anglès ha passat de tenir un paper quasi inexistent en la realització de preguntes per a la construcció de la ciència escolar a ser la mestra que realitza més preguntes d'aquest tipus.

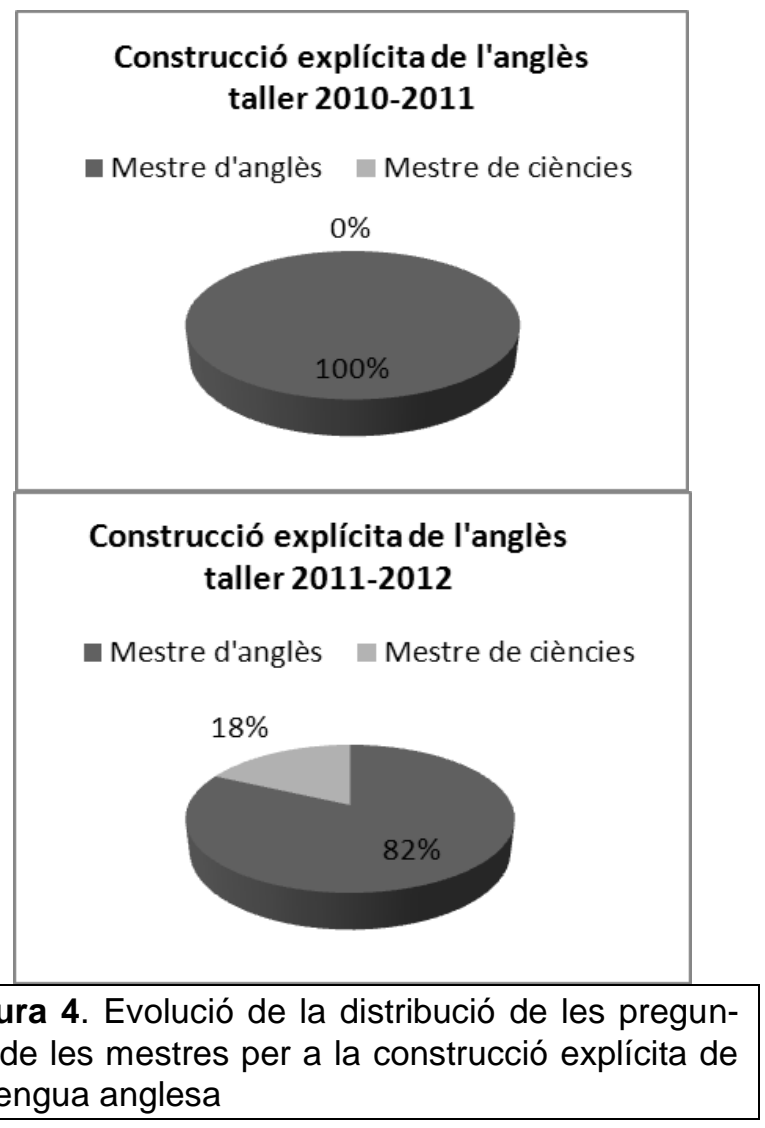


L'atenció explícita a la llengua anglesa, mitjançant metareflexions sobre el llenguatge, ha passat a ser promoguda també per les dues mestres, i a produir-se de forma natural en moments de conversa científica. La Figura 4 mostra con la mestra de ciències ha començat a fer preguntes d'anglès. A més la mestra de ciències ha incorporat vocabulari en anglès a les seves explicacions, tot i declarar que no té cap domini d'aquesta llengua.

En el taller corresponent al segon curs (20112012) s'han enregistrat moments en que la conversa científica és incentivada per la mestra d'anglès i d'altres en que la mestra de ciències inicia converses sobre la llengua anglesa, fet que no es donava durant el curs 2010-2011, en els moments inicials del Taller.

\section{CONCLUSIONS}

Diverses recerques ens han informat del benefici que l'AICLE pot generar per a l'ensenyamentaprenentatge tant de la llengua com del contingut. Engegar un projecte AICLE però, va més enllà de començar a impartir una assignatura en una altra llengua.

L'experiència de les dues mestres que hem relatat en aquest article ens ha ajudat a reflexionar sobre algunes aportacions que la docència compartida pot fer a enfocaments integradors de l'ensenyament - aprenentatge de les ciències i l'anglès. La planificació conjunta de materials adaptats, l'atenció a les dues disciplines, l'exposició correcte a la llengua estrangera i la formació del professorat que propicia, que es veu capacitat en poc temps per adquirir el rol de mestre d'una altra disciplina, fan de la docència compartida una bona eina per a la implementació d'un projecte AICLE a l'escola. Hem observat l'evolució d'una mestra d'anglès que ha estat capaç d'expandir la seva identitat i sentir-se còmode en el rol de mestra de ciències, i se'ns han plantejat noves preguntes sobre com es realitza aquest traspàs de competències professionals, sobre com s'aprèn a ensenyar ciències. Per exemple: quines dificultats concretes se li plantegen a un no especialista en ciències que es veu forçat a adquirir el rol de mestre de ciències? Quin tipus de preguntes de la classe de ciències són més difícils de realitzar des de la perspectiva del professorat no expert?

\section{BIBLIOGRAFIA}

CANET, P. Y EVNITSKAYA, N. (2011) Rethink, rewrite, remake or learning to teach science through English.A Escobar Urmeneta, C. et al. (Eds.) AICLE - CLIL - EMILE educació plurilingüe: Experiencias, research\& polítiques. (pp. 167-177) Bellaterra, Barcelona: Universitat Autònoma de Barcelona.

DALLARI, L., AGUAS, M., ESPINET, M. (2012, Mayo). Fer Ciències $i$ Anglès en tallers inter-nivel: una experiència CLIL a l'Educació Primària. TRICLIL 2012 Proceedings: Better CLIL. More opportunities in primary, secondary and higher education, Bellaterra, 10-11 Maig.

DALTON-PUFFER, C. (2007). Discourse in content and language integrated learning (CLIL) classrooms. Amsterdam; Philadelphia: John Benjamins.

DAVIS-WILLEY, P; CRESPO, A. (1998). Are Two Instructors Better Than One?: Planning, Teaching and Evaluating à Deux. Annual Meeting of the Mid-south Educational Research Association. New Orleans, Louisiana.

EDWARDS, D., \& MERCER, N. (1988). El conocimientocompartido: El desarrollo de la comprensión en el aula. Barcelona etc.: Paidós etc.

ESCOBAR URMENETA, C. et al. (2011) AICLE - CLIL - EMILE educació plurilingüe: Experiencias, research\& polítiques.Bellaterra, Barcelona: Universitat Autònoma de Barcelona.

EURYDICE (2006). Content and Language IntegratedLearning (CLIL) atSchool in Europe. Brussels:EurodyceEuropean Unit.Disponible a:http://eacea.ec.europa.eu/ressources/eurodyce/p df/0integral/071EN.pdf

GAJO, L (2007) Linguistic knowledge and subject knowledge: How does bilingualism contribute to subject development? International Journal of Bilingual Education and Bilingualism, 10:5, 563:581. Disponibleahttp://dx.doi.org/10.2167/beb460.0

GRANDY, R. iDuschl, R. (2008) Consensus: Expanding the scientific method and school science.A Duschl R., Grandy R. (Comps.) Teaching scientific inquiry: Recommendations for research and implementation(pp. 305-325).Rotterdam: SensePublishers.

MÁRQUEZ, C. I ROCA, M. (2006) Plantearbuenaspreguntas: un punto de partida para aprenderciencias. Educación y pedagogía, 18 (45), 63-71 
MOATE, J. (2011) Using a sociocultural CLIL pedagogical model to develop CLIL. A Escobar Urmeneta, C. (Ed.) AICLE - CLIL - EMILE educació plurilingüe: Experiencias, research\& polítiques. (pp. 101-110) Bellaterra, Barcelona: Universitat Autònoma de Barcelona.

MORTIMER, E., \& SCOTT, P. (2003). Meaning making in secondary science classrooms. Maidenhead: Open University Press.

ROTH, W., \& TOBIN, K. (2004) Coteaching: from praxis to theory. Teachers and teaching, 10(2), 161-179.Doi: 10.1080/1354060042000188017

ROTH, W., \& TOBIN, K. (2009).The world of science education. Rotterdam: Sense Publishers.

Sanmartí, N. (2002). Didáctica de las ciencias en la educación secundaria obligatoria. Madrid: Síntesis Educación.

VALDÉS, L. I ESPINET (2012) Construint l'aprenentatge integrat de ciències $i$ anglès a Pri- mària. Retrat d'una evolució fruit del coteaching i la pràctica autoreflexiva. Treball de fi de Màster. Bellaterra: Universitat Autònoma de Barcelona

VALDÉS, L., DALLARI, L., AGUAS, M. I ESPINET, M. (2012) Co-enseñando la indagación científica en inglés en talleres inter-nivel: una experiencia AICLE innovadora en Educación Primaria. Comunicació presentada a XXV Encuentro de Didáctica de las Ciencias Experimentales, Santiago de Compostela, 5-7 setembre. Reproduida a Domínguez, J.M (Ed.).(2012) XXV Encuentro de las Ciencias Experimentales. Santiago de Compostela: APICE y Universidad de Santiago de Compostela. ISBN: 97884-695-4673-4(pp. 771-792)

VALLBONA, A. (2011) Implementing CLIL in the Primary Calssroom: Results and challenges. A Escobar Urmeneta, C. et al. (Eds.) AICLE - CLIL EMILE educació plurilingüe: Experiencias, research\& polítiques. (pp. 151-158) Bellaterra, BarceIona: Universitat Autònoma de Barcelona. 